\title{
Ancient DNA Study in Medieval Europeans Shows an Association Between HLA-DRB1*03 and Paratyphoid Fever
}

OPEN ACCESS

Edited by:

Pedro Jose Esteves,

Centro de Investigacao em Biodiversidade e Recursos Geneticos

(CIBIO-InBIO), Portugal

Reviewed by: Jean Roudier,

Aix Marseille Université, France Javier Santander, Memorial University of Newfoundland,

Canada

${ }^{*}$ Correspondence:

Ben Krause-Kyora

b.krause-kyora@ikmb.uni-kiel.de

${ }^{\dagger}$ These authors have contributed equally to this work and share first authorship

Specialty section: This article was submitted to Comparative Immunology, a section of the journal

Frontiers in Immunology

Received: 06 April 2021 Accepted: 28 June 2021 Published: 15 July 2021

Citation:

Haller M, Bonczarowska JH,

Rieger D, Lenz TL, Nebel A

and Krause-Kyora B (2021) Ancient DNA Study in Medieval Europeans Shows an Association Between HLA-DRB $1^{*} 03$ and Paratyphoid Fever.

Front. Immunol. 12:691475. doi: 10.3389/fimmu.2021.691475
Magdalena Haller ${ }^{1 \dagger}$, Joanna H. Bonczarowska ${ }^{1 \dagger}$, Dirk Rieger ${ }^{2}$, Tobias L. Lenz ${ }^{3,4}$, Almut Nebel ${ }^{1}$ and Ben Krause-Kyora ${ }^{1 *}$

${ }^{1}$ Institute of Clinical Molecular Biology, Kiel University, Kiel, Germany, ${ }^{2}$ Department of Archaeology, Hanseatic City of Lübeck Historic Monuments Protection Authority, Lübeck, Germany, ${ }^{3}$ Research Group for Evolutionary Immunogenomics, Max Planck Institute for Evolutionary Biology, Plön, Germany, ${ }^{4}$ Research Unit for Evolutionary Immunogenomics, Department of Biology, Universität Hamburg, Hamburg, Germany

Outbreaks of infectious diseases repeatedly affected medieval Europe, leaving behind a large number of dead often inhumed in mass graves. Human remains interred in two burial pits from $14^{\text {th }}$ century CE Germany exhibited molecular evidence of Salmonella enterica Paratyphi C (S. Paratyphi $\mathrm{C}$ ) infection. The pathogen is responsible for paratyphoid fever, which was likely the cause of death for the buried individuals. This finding presented the unique opportunity to conduct a paratyphoid fever association study in a European population. We focused on HLA-DRB1 ${ }^{*} 03: 01$ that is a known risk allele for enteric fever in present-day South Asians. We generated HLA profiles for 29 medieval S. Paratyphi C cases and 24 contemporaneous controls and compared these to a modern German population. The frequency of the risk allele was higher in the medieval cases (29.6\%) compared to the contemporaneous controls (13\%; $p=0.189$ ), albeit not significantly so, possibly because of small sample sizes. Indeed, in comparison with the modern controls $(n=39,689 ; 10.2 \% ; p=0.005)$ the frequency difference became statistically significant. This comparison also suggested a slight decrease in the allele's prevalence between the medieval and modern controls. Up to now, this is the first study on the genetic predisposition to Salmonella infection in Europeans and the only association analysis on paratyphoid fever $\mathrm{C}$. Functional investigation using computational binding prediction between HLA variants and $S$. Paratyphi and $S$. Typhi peptides supported a reduced recognition capacity of bacterial proteins by $\mathrm{DRB} 1{ }^{*} 03: 01$ relative to other common DRB1 variants. This pattern could potentially explain the disease association. Our results suggest a slightly reduced predisposition to paratyphoid fever in modern Europeans. The causative allele, however, is still common today, which can be explained by a trade-off, as $\mathrm{DRB} 1{ }^{*} 03: 01$ is protective against infectious respiratory diseases such as severe respiratory syndrome (SARS). It is thus possible that the allele also provided resistance to corona-like viruses in the past.

Keywords: Salmonella enterica Paratyphi C, enteric fever, human leukocyte antigen, trade-off, antigen binding prediction 


\section{INTRODUCTION}

In Europe, infectious diseases were particularly common in the Middle Ages (1-6), occasionally reaching immense proportions and wreaking havoc across the whole continent. For instance, the infamous Black Death and subsequent plague outbreaks left behind millions of dead who, due to the scale of the pandemic, were often inhumed in mass burials (7). Studying past contagions is not only of interest from the historical perspective, but also important for our understanding of current and future epidemics. Excavation on the grounds of the medieval Heiligen-Geist-Hospital (HGH) in Lübeck, northern Germany, revealed the presence of two mass graves and two smaller burial pits (8-10). Molecular analysis of the human remains (1370 - $1400 \mathrm{CE})$ indicated that individuals buried in the pits were infected with Salmonella enterica subsp. enterica serovar Paratyphi $C$ at the time of death (11). The pathogen is a causative agent of paratyphoid fever, which is a lifethreatening illness transmitted through contaminated food and water (12). Nowadays $S$. Paratyphi C is virtually absent in Europe, however, it can be assumed that the pathogen's prevalence used to be higher in the past. Discovery of $S$. Paratyphi C in medieval Germany (11) and Norway (13) suggests a change in the geographic distribution of Salmonella enterica species over time. It is thus possible that paratyphoid fever used to have a substantial impact on the health of Europeans at that time (11). As the pathogen's genome is thought to have been stable for millennia (13), genetic factors of the host could have contributed to the disappearance of this infectious disease in modern Europe.

Apart from S. Paratyphi C, paratyphoid fever can be caused by two other Salmonella serovars (S. Paratyphi A and B). Clinically similar typhoid fever is caused by Salmonella Typhi and together with $S$. Paratyphi infections, the diseases are known under the umbrella term of enteric fever. Several genetic host factors have been previously associated with susceptibility to the disease (14-17). Among those factors is the polymorphic human leukocyte antigen (HLA) region. The high level of HLA variation together with a number of associations between HLA alleles and a variety of infectious diseases [e. g. (18-24)] suggests that pathogens have acted as a powerful selective pressure on the human genome as a result of host-pathogen co-evolution (2527). Regarding enteric fever, the HLA alleles $\mathrm{DRB}^{\star}{ }^{\star} 03: 01$ and $\mathrm{DRB} 1^{\star}$ 04:05 were identified as risk and protective factors, respectively, in present-day Vietnamese and Nepalese $(16,17)$. However, these associations were only shown for $S$. Typhi and $S$. Paratyphi A infections; as of yet, there are no studies exploring the genetic predisposition to $S$. Paratyphi $\mathrm{C}$ infections in modern populations. Nowadays the disease is very rare in Europe and usually a result of migrations from other regions of the world (12, $28,29)$. Thus, analysis of susceptibility to paratyphoid fever in European populations is only possible with an ancient DNA (aDNA) approach. In this study, we generated HLA genotype data for 53 skeletal remains from the $\mathrm{HGH}$ site and in particular examined the frequency of the $\mathrm{DRB} 1^{\star} 03: 01$ allele to assess whether variation at the DRB1 locus predisposed medieval Europeans to enteric infection.

\section{MATERIALS AND METHODS}

\section{Materials}

The skeletal material analyzed in this study was excavated from four mass burials (contexts 4528, 4529, 4562 and 4571) located near the Heiligen-Geist-Hospital ("Hospital of the Holy Ghost", HGH) in Lübeck, northern Germany (8-10). The graves were dug between 1340 and 1370 CE (11).

\section{DNA Extraction and Library Preparation}

Seventy individuals from the $\mathrm{HGH}$ site were analyzed in this study [Tables S1, Table S3 (11) for details on samples]. We sampled almost exclusively teeth and used the whole specimens for aDNA extraction. The DNA was isolated with the BioRobot ${ }^{\circledR}$ EZ1 Advanced applying a custom-made version of the LargeVolume-Protocol and the EZ1 DNA Investigator ${ }^{\circledR}$ Kit (Qiagen) as described previously $(11,30)$. The DNA extracts were then converted into indexed partial Uracil-DNA Glycosylase (UDG)treated libraries. The libraries were sequenced on an Illumina HiSeq 4000 platform. To reliably exclude contamination, all procedures were conducted in clean rooms specifically dedicated to ancient DNA analysis, and negative controls were included in both the extraction and library preparation steps. Furthermore, short tandem repeat profiles at seven loci were generated as an additional authentication criterion and to avoid double sampling Table S2 (11).

\section{HLA Targeted Capture and Typing}

In-solution enrichment of the HLA regions was successful for 53 of the 70 samples analyzed (excavation context 4528, $n=13$; $4529, n=11 ; 4562, n=6 ; 4571, n=23)$. Genotyping was performed using the semi-automated HLA-typing pipeline TARGT (Targeted Analysis of sequencing Reads for GenoTyping), which was designed for the analysis of lowcoverage sequences as found in aDNA extracts (31). The pipeline automatically identifies and sorts target-specific reads from sequence data. Subsequently, the sorted sequences were manually analyzed to determine the HLA alleles (HLA calling) in individual samples (31). In this study, the manual genotyping was done by three researchers independently, thus increasing the reliability of the results. In addition, we applied the algorithm OptiType (32), which is only available for class I genes, to verify class I allele calls obtained with the TARGT pipeline. The OptiType software (32) was used with default parameters. Only those samples that had alleles concordantly called by both methods were included in the results (Table S1).

\section{Computational Prediction of Peptide Binding by HLA}

Full proteomes of Salmonella enterica Paratyphi C RKS4594 (accession NC_012125.1, France) and S. enterica Typhi CT18 (accession NC_003198.1, Vietnam) were used to predict the binding of 15 mer peptides (967,163 and 1,201,560 possible 15 mers from $S$. Paratyphi and $S$. Typhi, respectively) for all DRB1 variants with an allele frequency $>1 \%$ in the present-day German population (AlleleFrequencies.net Database (AFND): Germany, Population $8, n=39,689$; 33). Peptide binding 
prediction was performed with the established algorithm NetMHCIIpan v4.0, using the default threshold for 'strong binding' (33). For each HLA-DRB1 variant, the total number of bound peptides overall as well as the total number of bacterial proteins 'recognized' (at least one peptide of a given protein predicted to be bound by the given HLA-DRB1 variant) were obtained.

\section{Statistical Analysis}

Fisher's exact test and odds ratio calculations were performed for the $\mathrm{DRB}^{\star} 03$ allele using IBM SPSS Statistics (Version 26) predictive analytics software. Power calculations on required sample sizes were calculated with the software $G^{*}$ Power, v3.1.9.2 (34). For $\mathrm{DRB} 1^{\star} 03: 01$, the power calculation showed that an association analysis was appropriate with our sample size. Assuming an OR of 4 (17), an allocation ratio of 10 and an allele frequency of $10.2 \%$ in modern controls (35), 28 alleles were required in cases to obtain an a priori power of $75 \%$ at a significance level of 0.05 .

\section{RESULTS}

In this study, we generated HLA genotype data from the skeletal remains of 53 individuals excavated from the HGH mass burial in Lübeck. The site consists of two mass graves (archaeological contexts 4528 and 4529) and two burial pits (4562 and 4571, Figure 1). Of the 70 metagenomic samples analyzed, 24 from 4528/4529 and 29 from 4562/4571 yielded HLA data after insolution DNA enrichment. Genotyping of the HLA alleles was performed for the class I (HLA-A, -B and -C) and class II (HLADQB1 and -DRB1) loci using the TARGT pipeline which is well suited to the analysis of low-coverage sequences (31) (Table S1). Despite such a dedicated pipeline, the highly degraded nature of aDNA (36) poses a severe challenge to HLA typing so that allele calling at the preferred $2^{\text {nd }}$-field (4-digit) resolution is not always possible. Nevertheless, even at $1^{\text {st }}$-field level of resolution, HLA typing can be highly informative, as it distinguishes among major functional groups ('supertypes') of classical HLA alleles. For the same reason, it was also not always possible to call alleles at both haplotypes, so that the total number of called alleles was lower than $2 \mathrm{~N}$. The investigation here was performed following the strategy outlined for an association study with aDNA data (20). As the individuals buried in the pits $(4562 / 4571)$ had been infected with $S$. Paratyphi C (11), they were considered cases in the association test (with 27 successfully called HLA-DRB1 alleles across the 29 individuals). The individuals buried in the mass graves (4528/ 4529) were used as contemporaneous controls (with 23 called HLA-DRB1 alleles across the 24 individuals), based on the fact that no molecular traces of the focal pathogen were observed in the remains (11). In a secondary analysis, allele frequencies in the historical cases were compared with a large cohort of modern individuals (AFND: Germany, Population 8, $n=39,689$; 33).

As $\mathrm{DRB} 1^{\star} 04: 05$ is protective against enteric fever, its frequency would be expected to be lower relative to the modern controls (0.45\%, Germany, AFND Population 8, $n=39,689$; 33). Thus, $\mathrm{DRB} 1^{\star} 04: 05$ was not investigated due to the case sample being too small for a meaningful statistical analysis based on the power calculation. On the contrary, for the $\mathrm{DRB1}^{\star} 03: 01$ risk allele, an association study was feasible making it the main focus of this investigation. Out of the 11 individuals with a $\mathrm{DRB} 1^{\star} 03$ allele call at $1^{\text {st }}$-field resolution, calls at $2^{\text {nd }}$-field resolution were possible for four individuals who consistently showed $\mathrm{DRB} 1^{\star} 03: 01$. Among the known alleles of the $\mathrm{DRB} 1^{\star} 03$ allele group, $\mathrm{DRB} 1^{\star} 03: 01$ is by far the most common in the modern German population (freq $=$ $10.2 \%)$, with the next frequent allele being two orders of magnitude less frequent $\left(\mathrm{DRB} 1^{\star} 03: 02\right.$, freq $\left.=0.1 \%\right)$. It is therefore highly likely that the other seven individuals with a DRB $1^{\star} 03$ call also carried the $\mathrm{DRB}^{\star}{ }^{\star} 03: 01$ allele, justifying an association analysis based on the $\mathrm{DRB} 1^{\star} 03$ calls. Moreover, four individuals were possibly homozygous for the $\mathrm{DRB}^{\star} 03$ type, given the available read depth and lack of other DRB1 sequences. However, a conservative approach was used here and these individuals were regarded as

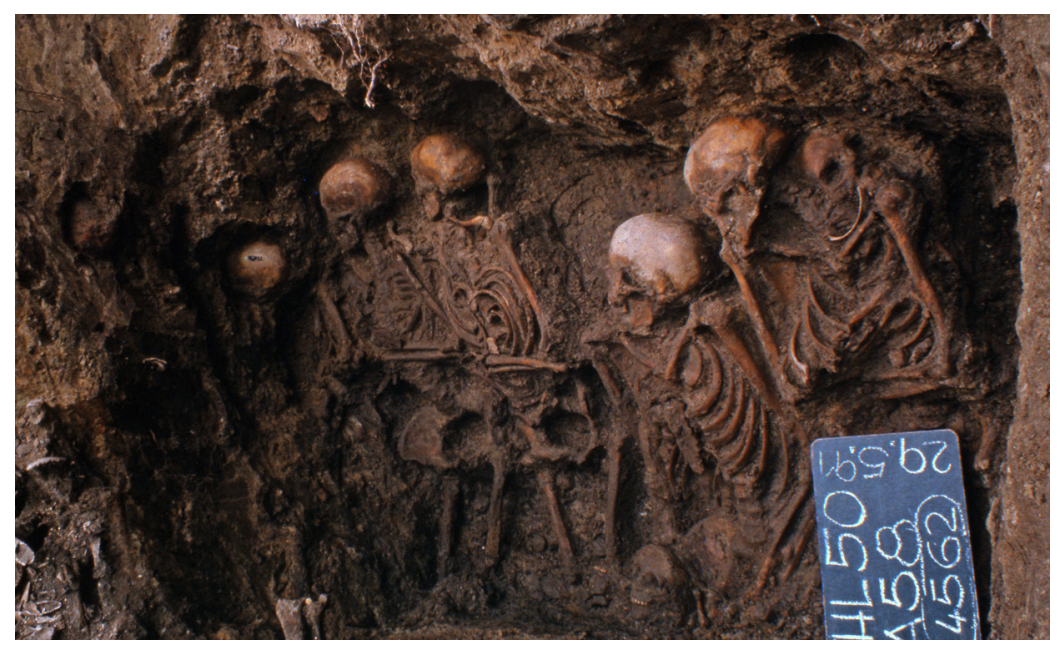

FIGURE 1 | Heiligen-Geist-Hospital (“Holy-Ghost-Hospital”) archaeological context 4562 in which S. Paratyphi C-positive individuals were found. 
heterozygotes. It is thus likely that the obtained frequency is underestimated. The frequency of the $\mathrm{DRB} 1^{\star} 03$ allele in the cases (29.6\%) was considerably higher in comparison to the contemporaneous controls $(13 \%, p=0.189)$, albeit it did not reach statistical significance, likely owing to the small sample sizes for the medieval groups. In line with this suggestive association result, the comparison of medieval cases with modern individuals yielded a frequency difference that was highly significant $(10.2 \%$; $p=$ 0.005 , OR $=3.61$ ) (Table S1). Interestingly, all four genotypes with a possible $2^{\text {nd }}$ field allele call of $\mathrm{DRB} 1^{\star} 03: 01$ also showed the alleles $\mathrm{DQB}^{\star} 02: 01$ or $\mathrm{DQB1}{ }^{\star} 02$ at the neighboring HLA-DQB1 locus (Table S1), which could be an indication of genetic linkage between $\mathrm{DRB}^{*}{ }^{\star} 03: 01$ and $\mathrm{DQB} 1^{\star} 02: 01$, a common haplotype in present-day populations (37).

Given the role of HLA molecules in peptide presentation for antigen-specific immunity, the binding of $S$. Paratyphi and $S$. Typhi peptides to common HLA-DRB1 variants was also explored, including the risk variant $\mathrm{DRB} 1^{\star} 03: 01$. Using computational peptide binding prediction, no particular difference in the total number of bound bacterial peptides was observed between the risk variant and the other DRB1 variants (Figure 2A). However, the number of 'recognized' bacterial proteins (defined as proteins of which at least one peptide was bound by a given HLA variant) was among the lowest for $\mathrm{DRB}^{\star}$ 03:01 compared to the other HLA variants (for both $S$. Paratyphi $C$ and $S$. Typhi; Figure 2B). This peculiarity in peptide binding of $\mathrm{DRB} 1^{\star} 03: 01$ became particularly evident when the number of proteins that were uniquely missed by each DRB1 variant (i.e., were predicted to be recognized by all other DRB1 variants but not the given one) were quantified. DRB1 ${ }^{\star}$ 03:01 missed $85 S$. Paratyphi proteins that were recognized by all other DRB1 variants, more than thrice the number compared to the other DRB1 variants (median $=26 \pm 16 \mathrm{SD}$, Figure 2C). A similar effect was observed for S. Typhi (Figure 2C).

\section{DISCUSSION}

In this study, variation at the HLA-DRB1 locus was investigated in the context of genetic susceptibility to $S$. Paratyphi C infection in human remains from Germany dating to the $14^{\text {th }}$ century CE. The DRB1*03:01 allele has been associated with an increased risk of enteric fever in modern Vietnamese and Nepalese populations (in this case caused by $S$. Typhi and $S$. Paratyphi A only) $(16,17)$. Up to date, no association study with an $S$. Paratyphi C infection has been performed in present-day populations, as it is relatively rare (38). However, there is evidence suggesting a high prevalence of this infectious disease in the Middle Ages $(11,13,39)$.

HLA typing was successfully performed for 53 individuals excavated from four archaeological contexts: two mass graves $(n=24)$ and two smaller pits $(n=29)$. Individuals buried in the pits were found to exhibit genetic traces of infection with $S$. Paratyphi C, likely representing the cause of death. The larger mass graves were stratigraphically older and no pathogen DNA was detected in the remains inhumed there (11). It has been previously hypothesized that individuals in the mass graves were victims of plague $(9,40)$. However, no evidence has been found to support these claims (11). In addition, to the best of our knowledge, no link between HLA variation and plague susceptibility has been reported in human association studies. Thus, even if plague was responsible for the death of the individuals in the mass graves, the disease was not expected to influence the frequencies of the examined allele. Based on these assumptions, the individuals from the mass graves were treated as contemporaneous controls for the medieval paratyphoid fever cases buried in the small pits. The cases were also compared to a representative modern German population from the AlleleFrequencies.net Database (35). As genetic continuity between the HGH Lübeck population and present-day northern Europeans was shown previously (11), it allows for such an analysis to be carried out. Furthermore, kinship was not detected among the medieval individuals (11). Our results indicate that the frequency of $\mathrm{DRB}^{\star} 03$ was significantly higher in the medieval paratyphoid fever cases in comparison to modern controls $(p=0.005)$. The obtained odds ratio of 3.6 is comparable to that in previous reports for enteric fever in modern South Asian populations $(16,17)$. The $\mathrm{DRB}{ }^{\star} 03$ frequency in the cases (29.6\%) was also substantially higher relative to medieval controls $(13 \%)$. Although calls at $2^{\text {nd }}$-field resolution (i.e., $\left.\mathrm{DRB} 1^{\star} 03: 01\right)$ were only possible for four individuals, all $\mathrm{DRB} 1^{\star} 03$ calls were interpreted as $\mathrm{DRB} 1{ }^{\star} 03: 01$, since this allele is by far the most common within the $\mathrm{DRB} 1^{\star} 03$ group in Germans today (35).

This is the first report of an allelic association with an $S$. Paratyphi $\mathrm{C}$ infection. However, due to the relatively small number of specimens available for the present study, an inherent limitation of aDNA studies, this finding should be confirmed in a larger sample comprised of Far Eastern populations in which the disease is still common today (12). Nevertheless, as paratyphoid fever is no longer endemic in Europe, aDNA analysis is the only approach that allows us to explore whether $\mathrm{DRB} 1^{\star} 03: 01$ is involved in genetic predisposition to an $S$. Paratyphi C infection in Europeans.

The functional follow-up analysis, using a computational algorithm for prediction of binding between HLA variants and bacterial peptides, revealed an interesting pattern for the HLADRB1 risk variant that could potentially explain its association with susceptibility. The variant $\mathrm{DRB} 1^{\star} 03: 01$ was predicted to miss recognition (i.e., fail to bind at least one peptide) of the largest number of bacterial proteins that were recognized by all other common DRB1 variants. However, it should be noted that the number of missed proteins was small compared to the total number of proteins in the bacterial proteomes. It thus remains to be investigated whether this peculiar binding pattern of DRB1*03:01 would significantly affect susceptibility of its carriers.

The decreased frequency of the HLA risk allele in the modern population $(10.2 \%)$ relative to the medieval controls (13\%) might indicate slight negative selection. The limited available sample size for ancient remains for both cases and contemporaneous controls 


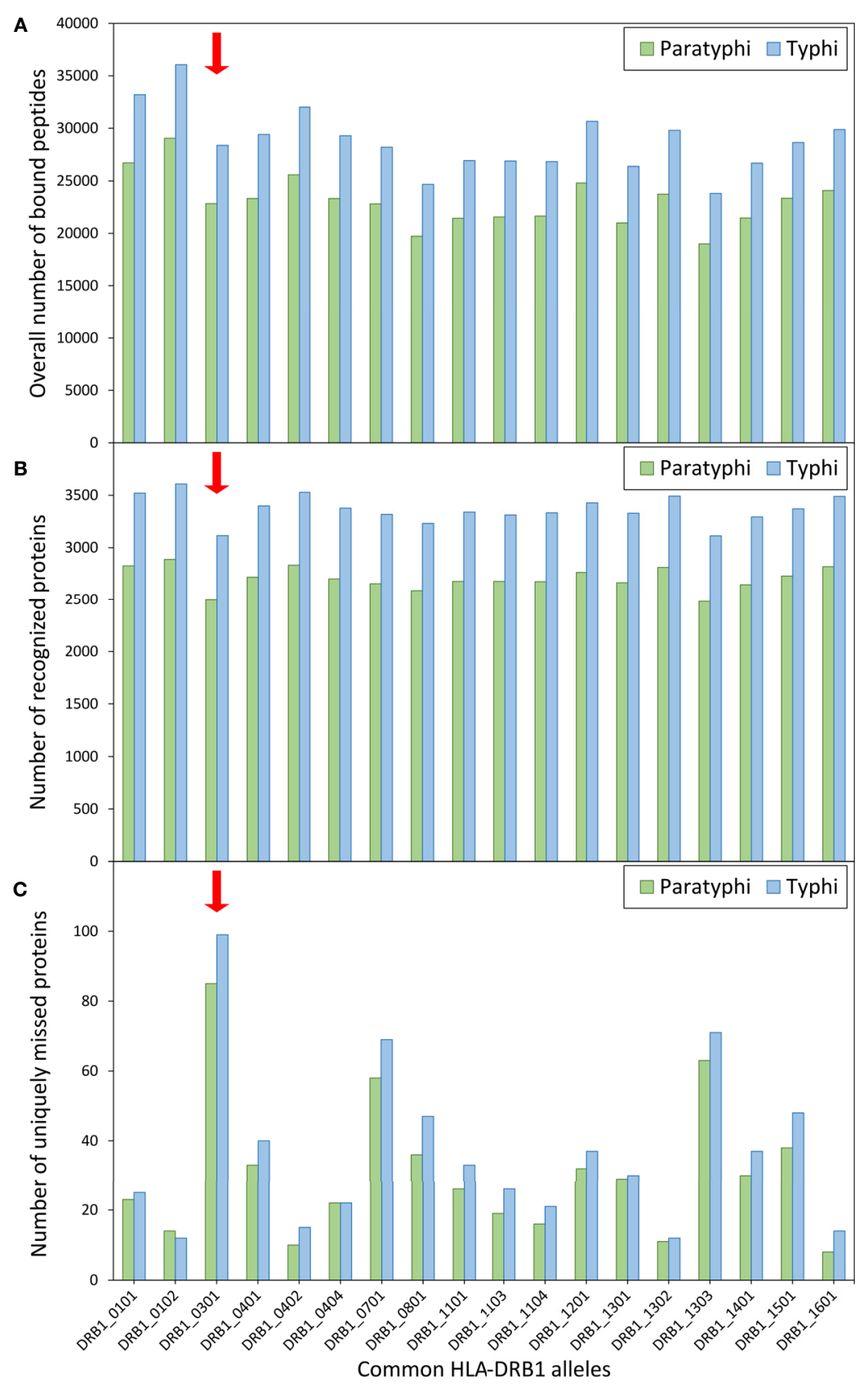

FIGURE 2 | Computationally predicted binding of common HLA-DRB1 variants to bacterial peptides. Binding prediction was performed for all HLA-DRB1 variants with allele frequency $>1 \%$ in present-day Germany ( $n=18)$, using the full proteomes of both Salmonella enterica Paratyphi $\mathrm{C}$ (green bars) and S. Typhi (blue bars). For each DRB1 variant, (A) the overall number of bound peptides, (B) the total number of 'recognized' proteins (at least one peptide bound by a given DRB1 variant), and $(\mathbf{C})$ the number of uniquely 'missed' proteins (recognized by all other variants) are shown.

prevents any strong conclusion about the potential selective effect of this association. However, in view of the negative effect of $\mathrm{DRB} 1^{\star} 03: 01$, it is tempting to speculate about a trade-off that might explain as to why this allele is still present at such a high frequency today. Interestingly, the allele was shown to be protective against severe acute respiratory syndrome (SARS) infection in the modern Chinese population (41-43). Although currently there is no data confirming this association for present-day Europeans, it is possible that ancient epidemics of paratyphoid fever affected the level of genetic resistance against SARS, predisposing present-day Europeans to an infection with the causative coronavirus. There is further evidence linking $\mathrm{DRB} 1^{\star}$ 03:01 with various respiratory diseases such as resistance to tuberculosis (44). It is therefore conceivable that this allele was protective against corona-like 
viruses or other infectious agents in the past. In addition, it has been suggested that $\mathrm{DRB} 1^{\star} 03: 01$ provides protection against allergy to animal-derived proteins (dairy and eggs) $(45,46)$. Recently, we discovered that the allele was absent in a Neolithic population of 23 individuals (47). This observation is striking when considered in the context of dietary changes that were introduced with the Neolithic agricultural transition. All these factors and the notable presence of $\mathrm{DRB}^{\star}{ }^{\star} 03: 01$ in the current gene pool indicate that this HLA allele has been subject to balancing selection. $\mathrm{DRB} 1^{\star} 03: 01$ is a risk factor for type I diabetes, autoimmune hepatitis, multiple sclerosis, celiac disease, sarcoidosis, Grave's disease, systemic lupus erythematosus and Sjörgen's syndrome in modern populations across the globe (48-55). Due to the relatively low number of pathogens in the modern environment, negative effects of this HLA allele might now predominate, contributing to the increasing prevalence of inflammatory and autoimmune diseases today.

\section{DATA AVAILABILITY STATEMENT}

The datasets generated for this study can be found in the European Nucleotide Archive under the accession number PRJEB42927.

\section{ETHICS STATEMENT}

Ethical review and approval were not required for the study on human participants in accordance with the local legislation and institutional requirements.

\section{REFERENCES}

1. Boldsen JL. Leprosy and Mortality in the Medieval Danish Village of Tirup. Am J Phys Anthropol (2005) 126:159-68. doi: 10.1002/ajpa.20085

2. Dangvard Pedersen D, Milner GR, Kolmos HJ, Boldsen JL. Tuberculosis in Medieval and Early Modern Denmark: A Paleoepidemiological Perspective. Int J Paleopathol (2019) 27:101-8. doi: 10.1016/j.ijpp.2018.11.003

3. Hopkins DR. Greatest Killer: Smallpox in History. Chicago: University of Chicago Press (2002). 415 p.

4. Mühlemann B, Vinner L, Margaryan A, Wilhelmson H, de La Fuente Castro C, Allentoft ME, et al. Diverse Variola Virus (Smallpox) Strains Were Widespread in Northern Europe in the Viking Age. Science (2020) 369: eaaw8977. doi: 10.1126/science.aaw8977

5. Schuenemann VJ, Avanzi C, Krause-Kyora B, Seitz A, Herbig A, Inskip S, et al. Ancient Genomes Reveal a High Diversity of Mycobacterium Leprae in Medieval Europe. PloS Pathog (2018) 14:e1006997. doi: 10.1371/journal. ppat.1006997

6. Spyrou MA, Keller M, Tukhbatova RI, Scheib CL, Nelson EA, Andrades Valtueña A, et al. Phylogeography of the Second Plague Pandemic Revealed Through Analysis of Historical Yersinia Pestis Genomes. Nat Commun (2019) 10:4470. doi: 10.1038/s41467-019-12154-0

7. Willmott H, Townend P, Swales DM, Poinar H, Eaton K, Klunk J. A Black Death Mass Grave at Thornton Abbey: The Discovery and Examination of a FourteenthCentury Rural Catastrophe. Antiquity (2020) 94:179-96. doi: 10.15184/aqy.2019.213

8. Lütgert SA. "Archäologische Untersuchungen der Massenbestattungen am Heiligen-Geist-Hospital zu Lübeck: Auswertung der Befunde und Funde”. In: M Gläser, editor. Lübecker Schriften zu Archäologie und Kulturgeschichte 26. Bonn: Rudolf Habelt (2002). p. 139-243.

9. Prechel M. "Anthropologische Untersuchungen der Skelettreste aus einem Pestmassengrab am Heiligen-Geist-Hospital zu Lübeck”. In: GP Fehring,

\section{AUTHOR CONTRIBUTIONS}

$\mathrm{BK}-\mathrm{K}$ conceived and designed the study. $\mathrm{MH}$ generated aDNA data. $\mathrm{MH}, \mathrm{JB}$, and $\mathrm{TL}$ analyzed the data. $\mathrm{MH}, \mathrm{JB}, \mathrm{TL}, \mathrm{AN}$, and $B K-K$ interpreted the results. DR provided data and interpretation on the archaeological material. JB, MH, TL, AN, and $\mathrm{BK}-\mathrm{K}$ wrote the manuscript. All authors contributed to the article and approved the submitted version.

\section{FUNDING}

This study was supported by the Deutsche Forschungsgemeinschaft (DFG, German Research Foundation) through the projects 2901391021 (CRC 1266), 437857095 and Germany's Excellence Strategy EXC2167-390884018. JB was funded by the International Max Planck Research School for Evolutionary Biology.

\section{ACKNOWLEDGMENTS}

We thank Edma Loku for her help with the genotype calling.

\section{SUPPLEMENTARY MATERIAL}

The Supplementary Material for this article can be found online at: https://www.frontiersin.org/articles/10.3389/fimmu.2021.691475/ full\#supplementary-material

editor. Lübecker Schriften zu Archäologie und Kulturgeschichte 24. Bonn: Rudolf Habelt (1996). p. 323-39.

10. Prechel M. "Eine Lübecker Population von 1350. Krankheiten und Mangelerscheinungen: Archäologische Untersuchungen auf dem Lübecker Stadthügel: Befunde und Funde". In: M Gläser, editor. Lübecker Schriften zu Archäologie und Kulturgeschichte 26. Bonn: Rudolf Habelt (2002). p. 245-86.

11. Haller M, Callan K, Susat J, Flux AL, Immel A, Franke A, et al. Mass Burial Genomics Reveals Outbreak of Enteric Paratyphoid Fever in the Late Medieval Trade City Lübeck. iScience (2021) 24:102419. doi: 10.1016/j.isci.2021.102419

12. Crump JA, Mintz ED. Global Trends in Typhoid and Paratyphoid Fever. Clin Infect Dis (2010) 50:241-6. doi: 10.1086/649541

13. Zhou Z, Lundstrøm I, Tran-Dien A, Duchêne S, Alikhan N-F, Sergeant MJ, et al. Pan-Genome Analysis of Ancient and Modern Salmonella Enterica Demonstrates Genomic Stability of the Invasive Para C Lineage for Millennia. Curr Biol (2018) 28:2420-28.e10. doi: 10.1016/j.cub.2018.05.058

14. Ali S, Vollaard AM, Widjaja S, Surjadi C, van de Vosse E, van Dissel JT. PARK2/PACRG Polymorphisms and Susceptibility to Typhoid and Paratyphoid Fever. Clin Exp Immunol (2006) 144:425-31. doi: 10.1111/ j.1365-2249.2006.03087.x

15. Alvarez MI, Glover LC, Luo P, Wang L, Theusch E, Oehlers SH, et al. Human Genetic Variation in VAC14 Regulates Salmonella Invasion and Typhoid Fever Through Modulation of Cholesterol. Proc Natl Acad Sci USA (2017) 114:E7746-55. doi: 10.1073/pnas.1706070114

16. Dunstan SJ, Stephens HA, Blackwell JM, Duc CM, Lanh MN, Dudbridge F, et al. Genes of the Class II and Class III Major Histocompatibility Complex Are Associated With Typhoid Fever in Vietnam. J Infect Dis (2001) 183:261-8. doi: $10.1086 / 317940$

17. Dunstan SJ, Hue NT, Han B, Li Z, Tram TT, Sim KS, et al. Variation at HLADRB1 is Associated With Resistance to Enteric Fever. Nat Genet (2014) 46:1333-6. doi: 10.1038/ng.3143 
18. Asti M, Martinetti M, Zavaglia C, Cuccia MC, Gusberti L, Tinelli C, et al. Human Leukocyte Antigen Class II and III Alleles and Severity of Hepatitis C Virus-Related Chronic Liver Disease. Hepatology (1999) 29:1272-9. doi: 10.1002/hep.510290445

19. Hu J, Li L, Pang L, Chen Y, Yang L, Liu C, et al. Hla-DRB1*1501 and HLADQB $1^{\star} 0301$ Alleles are Positively Associated With HPV16 InfectionRelated Kazakh Esophageal Squamous Cell Carcinoma in Xinjiang China. Cancer Immunol Immunother (2012) 61:2135-41. doi: 10.1007/ s00262-012-1281-x

20. Krause-Kyora B, Nutsua M, Boehme L, Pierini F, Pedersen DD, Kornell S-C, et al. Ancient DNA Study Reveals HLA Susceptibility Locus for Leprosy in Medieval Europeans. Nat Commun (2018) 9:1569. doi: 10.1038/s41467-01803857-x

21. Mbarek H, Ochi H, Urabe Y, Kumar V, Kubo M, Hosono N, et al. A GenomeWide Association Study of Chronic Hepatitis B Identified Novel Risk Locus in a Japanese Population. Hum Mol Genet (2011) 20:3884-92. doi: 10.1093/hmg/ ddr301

22. Sveinbjornsson G, Gudbjartsson DF, Halldorsson BV, Kristinsson KG, Gottfredsson M, Barrett JC, et al. HLA Class II Sequence Variants Influence Tuberculosis Risk in Populations of European Ancestry. Nat Genet (2016) 48:318-22. doi: 10.1038/ng.3498

23. Zhang F, Liu H, Chen S, Wang C, Zhu C, Zhang L, et al. Evidence for an Association of HLA-DRB1 ${ }^{*} 15$ and DRB $1^{*} 09$ With Leprosy and the Impact of DRB $1^{*} 09$ on Disease Onset in a Chinese Han Population. BMC Med Genet (2009) 10:133. doi: 10.1186/1471-2350-10-133

24. Arora J, Pierini F, McLaren PJ, Carrington M, Fellay J, Lenz TL. HLA Heterozygote Advantage Against HIV-1 Is Driven by Quantitative and Qualitative Differences in HLA Allele-Specific Peptide Presentation. Mol Biol Evol (2020) 37:639-50. doi: 10.1093/molbev/msz249

25. Field Y, Boyle EA, Telis N, Gao Z, Gaulton KJ, Golan D, et al. Detection of Human Adaptation During the Past 2000 Years. Science (2016) 354:760-4. doi: 10.1126/science.aag0776

26. Penn DJ, Damjanovich K, Potts WK. MHC Heterozygosity Confers a Selective Advantage Against Multiple-Strain Infections. Proc Natl Acad Sci USA (2002) 99:11260-4. doi: 10.1073/pnas.162006499

27. Fumagalli M, Sironi M, Pozzoli U, Ferrer-Admetlla A, Ferrer-Admettla A, Pattini L, et al. Signatures of Environmental Genetic Adaptation Pinpoint Pathogens as the Main Selective Pressure Through Human Evolution. PloS Genet (2011) 7:e1002355. doi: 10.1371/journal.pgen.1002355

28. Achtman M, Wain J, Weill F-X, Nair S, Zhou Z, Sangal V, et al. Multilocus Sequence Typing as a Replacement for Serotyping in Salmonella Enterica. PloS Pathog (2012) 8:e1002776. doi: 10.1371/journal.ppat.1002776

29. Uzzau S, Brown DJ, Wallis T, Rubino S, Leori G, Bernard S, et al. Host Adapted Serotypes of Salmonella Enterica. Epidemiol Infect (2000) 125:22955. doi: $10.1017 / \mathrm{S} 0950268899004379$

30. Fehren-Schmitz L, Reindel M, Cagigao ET, Hummel S. Pre-Columbian Population Dynamics in Coastal Southern Peru: A Diachronic Investigation of mtDNA Patterns in the Palpa Region by Ancient DNA Analysis. Am J Phys Anthropol (2010) 141:208-21. doi: 10.1002/ajpa.21135

31. Pierini F, Nutsua M, Böhme L, Özer O, Bonczarowska J, Susat J, et al. Targeted Analysis of Polymorphic Loci From Low-Coverage Shotgun Sequence Data Allows Accurate Genotyping of HLA Genes in Historical Human Populations. Sci Rep (2020) 10:7339. doi: 10.1038/s41598-02064312-w

32. Szolek A, Schubert B, Mohr C, Sturm M, Feldhahn M, Kohlbacher O. OptiType: Precision HLA Typing From Next-Generation Sequencing Data. Bioinformatics (2014) 30:3310-6. doi: 10.1093/bioinformatics/ btu548

33. Reynisson B, Alvarez B, Paul S, Peters B, Nielsen M. NetMHCpan-4.1 and NetMHCIIpan-4.0: Improved Predictions of MHC Antigen Presentation by Concurrent Motif Deconvolution and Integration of MS MHC Eluted Ligand Data. Nucleic Acids Res (2020) 48:W449-54. doi: 10.1093/nar/ gkaa379

34. Faul F, Erdfelder E, Buchner A, Lang A-G. Statistical Power Analyses Using $\mathrm{G}^{*}$ Power 3.1: Tests for Correlation and Regression Analyses. Behav Res Methods (2009) 41:1149-60. doi: 10.3758/BRM.41.4.1149

35. Gonzalez-Galarza FF, McCabe A, Santos EJ, Jones J, Takeshita L, OrtegaRivera ND, et al. Allele Frequency Net Database (AFND) 2020 Update: Gold-
Standard Data Classification, Open Access Genotype Data and New Query Tools. Nucleic Acids Res (2020) 48:D783-8. doi: 10.1093/nar/gkz1029

36. Dabney J, Meyer M, Pääbo S. Ancient DNA damage. Cold Spring Harb Perspect Biol (2013) 5:a012567. doi: 10.1101/cshperspect.a012567

37. Zhang R, Duffy BF, Lange V, Eby CS, Liu C. Association Between the HLA-DRB1*03:01-DQB1*02:01 Haplotype and PF4/heparin Antibodies. Blood Adv (2019) 3:3136-42. doi: 10.1182/bloodadvances. 2019000311

38. Appiah GD, Hughes MJ, Chatham-Stephens K. "Typhoid \& Paratyphoid Fever". In: CDC Yellow Book 2020: Health Information for International Travel. New York: Oxford University Press (2020).

39. Vågene ÅJ, Herbig A, Campana MG, Robles García NM, Warinner C, Sabin S, et al. Salmonella Enterica Genomes From Victims of a Major SixteenthCentury Epidemic in Mexico. Nat Ecol Evol (2018) 2:520-8. doi: 10.1038/ s41559-017-0446-6

40. Koppmann K. Die Chroniken der niedersächsischen Städte, Lübeck, Band 2. Leipzig: S. Hirzel (1899).

41. Wang S-F, Chen K-H, Chen M, Li W-Y, Chen Y-J, Tsao C-H, et al. HumanLeukocyte Antigen Class I Cw 1502 and Class II DR 0301 Genotypes are Associated With Resistance to Severe Acute Respiratory Syndrome (SARS) Infection. Viral Immunol (2011) 24:421-6. doi: 10.1089/ vim.2011.0024

42. Ng MH, Lau K-M, Li L, Cheng S-H, Chan WY, Hui PK, et al. Association of Human-Leukocyte-Antigen Class I (B*0703) and Class II (DRB1*0301) Genotypes With Susceptibility and Resistance to the Development of Severe Acute Respiratory Syndrome. J Infect Dis (2004) 190:515-8. doi: 10.1086/ 421523

43. Sanchez-Mazas A. HLA Studies in the Context of Coronavirus Outbreaks. Swiss Med Wkly (2020) 150:w20248. doi: 10.4414/smw.2020.20248

44. Malkova A, Starshinova A, Zinchenko Y, Basantsova N, Mayevskaya V, Yablonskiy P, et al. The Opposite Effect of Human Leukocyte Antigen Genotypes in Sarcoidosis and Tuberculosis: A Narrative Review of the Literature. ERJ Open Res (2020) 6:00155-2020. doi: 10.1183/23120541. 00155-2020

45. Dimitrov I, Doytchinova I. Associations Between Milk and Egg Allergens and the HLA-DRB1/DQ Polymorphism: A Bioinformatics Approach. Int Arch Allergy Immunol (2016) 169:33-9. doi: 10.1159/000444172

46. Ogrodowczyk AM, Dimitrov I, Wróblewska B. Two Faces of Milk Proteins Peptides With Both Allergenic and Multidimensional Health Beneficial Impact- Integrated. In Vitro/In Silico Approach. Foods (2021) 10:163. doi: 10.3390/foods 10010163

47. Immel A, Pierini F, Rinne C, Meadows J, Barquera R, Szolek A, et al. GenomeWide Study of a Neolithic Wartberg Grave Community Reveals Distinct HLA Variation and Hunter-Gatherer Ancestry. Commun Biol (2021) 4:113. doi: 10.1038/s42003-020-01627-4

48. Chen QY, Huang W, She JX, Baxter F, Volpe R, Maclaren NK. HLA$\mathrm{DRB}^{*} 08, \mathrm{DRB}^{*} 03 / \mathrm{DRB}^{*} 0101$, and $\mathrm{DRB} 3^{*} 0202$ are Susceptibility Genes for Graves' Disease in North American Caucasians, Whereas DRB1*07 is Protective. J Clin Endocrinol Metab (1999) 84:3182-6. doi: 10.1210/ jcem.84.9.5991

49. Cruz-Tapias P, Pérez-Fernández OM, Rojas-Villarraga A, RodríguezRodríguez A, Arango M-T, Anaya J-M. Shared HLA Class II in Six Autoimmune Diseases in Latin America: A Meta-Analysis. Autoimmune Dis (2012) 2012:569728. doi: 10.1155/2012/569728

50. Fernando MM, Stevens CR, Sabeti PC, Walsh EC, McWhinnie AJ, Shah A, et al. Identification of Two Independent Risk Factors for Lupus Within the MHC in United Kingdom Families. PloS Genet (2007) 3:e192. doi: 10.1371/ journal.pgen.0030192

51. Kwon OJ, Karni A, Israel S, Brautbar C, Amar A, Meiner Z, et al. HLA Class II Susceptibility to Multiple Sclerosis Among Ashkenazi and non-Ashkenazi Jews. Arch Neurol (1999) 56:555-60. doi: 10.1001/archneur.56.5.555

52. Morris DL, Taylor KE, Fernando MM, Nititham J, Alarcón-Riquelme ME, Barcellos LF, et al. Unraveling Multiple MHC Gene Associations With Systemic Lupus Erythematosus: Model Choice Indicates a Role for HLA Alleles and Non-HLA Genes in Europeans. Am J Hum Genet (2012) 91:77893. doi: 10.1016/j.ajhg.2012.08.026

53. Nakken B, Jonsson R, Brokstad KA, Omholt K, Nerland AH, Haga HJ, et al. Associations of MHC Class II Alleles in Norwegian Primary Sjögren's 
Syndrome Patients: Implications for Development of Autoantibodies to the Ro52 Autoantigen. Scand J Immunol (2001) 54:428-33. doi: 10.1046/j.13653083.2001.00993.x

54. Shankarkumar U, Ghosh K, Badakere SS, Mohanty D. HLA-DRB1*03 and DQB1*0302 Associations in a Subset of Patients Severely Affected With Systemic Lupus Erythematosus From Western India. Ann Rheum Dis (2003) 62:92-3. doi: 10.1136/ard.62.1.92

55. van Gerven NM, de Boer YS, Zwiers A, Verwer BJ, Drenth JP, Van Hoek B, et al. HLA-DRB1 ${ }^{\star} 03: 01$ and HLA-DRB1 ${ }^{\star} 04: 01$ Modify the Presentation and Outcome in Autoimmune Hepatitis Type-1. Genes Immun (2015) 16:247-52. doi: 10.1038 /gene.2014.82
Conflict of Interest: The authors declare that the research was conducted in the absence of any commercial or financial relationships that could be construed as a potential conflict of interest.

Copyright (C) 2021 Haller, Bonczarowska, Rieger, Lenz, Nebel and Krause-Kyora. This is an open-access article distributed under the terms of the Creative Commons Attribution License (CC BY). The use, distribution or reproduction in other forums is permitted, provided the original author(s) and the copyright owner(s) are credited and that the original publication in this journal is cited, in accordance with accepted academic practice. No use, distribution or reproduction is permitted which does not comply with these terms. 